\title{
Magnitude estimation of temporal intervals
}

\author{
LORRAINE G. ALLAN \\ McMaster University, Hamilton, Ontario, Canada
}

\begin{abstract}
Data are presented from a magnitude estimation study of temporal intervals. The individual subject data do not support the lognormal model of error. Many of the response distributions are negatively skewed, and, in general, the variance of the log responses decreases with stimulus duration. The fit of the two-parameter power function, obtained using nonlinear estimation, is compared with the fit obtained using linear least squares in $\log -\log$ coordinates. Nonlinear estimation provides a better description of the individual subject data and yields estimates of the exponent which are closer to 1.00 . The addition of a third parameter brings the exponents very close to 1.00 . It is concluded that, since the value of the power function exponent depends upon the curve-fitting procedure used, magnitude estimation data do not provide compelling evidence against a linear psychophysical function for time.
\end{abstract}

Most magnitude estimation studies have concluded that estimates are a power function of stimulus values. This claim has also been made for temporal intervals by many investigators (for example, Bobko, Thompson, \& Schiffman, 1977; Eisler, 1975, 1976; Jones \& McLean, 1966; Künnapas, Hallsten, \& Söderberg, 1973; Mashour \& Hosman, 1968; Michon, 1967; Painton, Cullinan, \& Mencke, 1977; Steiner, 1968; S. S. Stevens \& Galanter, 1957; S. S. Stevens \& Greenbaum, 1966). While, in a number of these studies (Bobko et al., 1977; Jones \& McLean, 1966; S. S. Stevens \& Galanter, 1957; S. S. Stevens \& Greenbaum, 1966), the estimate of the power function exponent is very close to 1.00 , averaged over many studies the value is about .90 (Eisler, 1976). The deviation of the exponent from unity, on average, has been taken to indicate that time perception is not veridical. This conclusion runs counter to that reached on the basis of data from duration discrimination tasks. A number of decision theory models specify that the expected value of the internal duration distribution is a linear function of stimulus duration (Allan, Kristofferson, \& Wiens, 1971; Creelman, 1962; Kinchla, 1972). A large quantity of data has been analyzed in terms of these models, and, in general, the data are in accord with the linear assumption of the models. More recently, Kristofferson $(1977,1980)$ has shown that, under some circumstances, duration discrimination data are compatible with the real-time criterion model, which states that, for the purpose of discrimination, there is no trans-

This investigation was supported by a grant from the Natural Sciences and Engineering Research Council of Canada. Cem Kaner ran the subjects and carried out many of the statistical analyses. The data described in this paper are those referred to in Note 3 in Allan (1979). Requests for reprints should be directed to Lorraine G. Allan, Psychology Department, McMaster University, Hamilton, Ontario L8S 4K1, Canada. formation of stimulus time into psychological time. According to this model, internal time is real time.

Allan (1979) distinguished between duration scaling tasks, which include the magnitude estimation task, and duration discrimination tasks. In a duration scaling task, the subject is asked about the perceived duration of a set of easily discriminable temporal intervals, whereas in a duration discrimination task, the subject is asked to distinguish among a set of highly confusable intervals. At first glance, one might think that scaling and discrimination tasks lead to different conclusions regarding the subjective time scale. In fact, there are data from another scaling task, ratio-setting, which are often cited in support of the power function as the psychophysical law for temporal intervals. In a ratio-setting task, a standard duration is presented to the subject and he is required to set a variable duration so that it is a specified proportion, $P$, of the standard. Most frequently, the empirical relationship between variable setting and standard duration is linear. Eisler (1974, Note 1) and Ekman (Note 2) showed that the power function as the psychophysical law is compatible with this empirical linear relationship, and they developed models for ratio-setting data (Eisler, 1975; Frankenhauser, 1960; Ekman \& Frankenhauser, Note 3). Allan (1978) and Blankenship and Anderson (1976) have criticized these models. Allan (1978) pointed out that, in order to evaluate the models, it is necessary to assume that the ratio specified by the experimenter, $P$, is that used by the subject. She demonstrated that when this assumption is made, the estimated exponent did not remain constant as $P$ was varied.

In commenting on Allan's analysis, Eisler (1981b) agreed that "equality between the ratio prescribed by the experimenter and the subjective ratio corresponding to it is a necessary condition for the computation of a valid exponent. I likewise concede that this con- 
dition is not always met-although with the exception of duration reproduction, which formally corresponds to a ratio of unity .... [T]he observer functions as a null instrument with no opportunity to deviate from the prescribed ratio .... [E]xponents obtained from reproduction should be correct, whereas data based on other ratios may or may not agree" (p. 518). The power in Eisler's (1975) parallel-clock model resides in its ability to extract the same value of the exponent across different ratio-setting tasks. However, if only reproduction exponents can be estimated, the model loses its appeal. Moreover, the empirical linear relationship between variable setting and standard duration, as Allan (1978) noted, is compatible with a linear psychophysical law for temporal intervals.

Support for a linear psychophysical function has been demonstrated in two quite different scaling tasks, category ratings of duration intervals and synchronization of a response with a temporal event. Curtis and Rule (1977) applied their two-stage model to category ratings of temporal intervals, and Blankenship and Anderson (1976) made use of the functional measurement approach (see Anderson, 1977) in analyzing their data. The data from both category rating studies are consistent with a linear psychophysical function. Hopkins (1982), Hopkins and Kristofferson (1980), and Kristofferson (1976) have presented synchronization data that are in agreement with the view that internal time is real time.

Eisler (1981a, 1981b) has argued that his parallelclock model, which postulates the power function as the psychophysical law, can account for discrimination data. Eisler (1981a) reanalyzed Allan's (1977) discrimination data and found that, while a single three-parameter power function did not provide a good fit to the data, a segmented function did. However, as Eisler (1981a, Footnote 6) himself notes, he cannot provide a convincing account for the break in the function. Eisler (1981b) also suggested that his model can account for important aspects of Kristofferson's (1977) data. Kristofferson used the many-to-few, single-stimulus task (Allan \& Kristofferson, 1974), with four stimulus durations and two response alternatives. He showed that, with extended training, the shortest and longest durations were perfectly discriminated. Eisler (1981 b) attempts to show that his model can account for this result. In his proof, he takes the special cases of the shortest duration on Trial $n-1$ followed by the shortest on Trial $n$, and of the longest duration on Trial $n-1$ followed by the longest on Trial $n$. His analysis implies that a correct response on Trial $\mathbf{n}$ depends upon the duration value on Trial $n-1$. There is no indication of this dependency in the data (Kristofferson, Note 4). It is our view that Eisler has not presented a strong case for his model in relation to discrimination data.
There is considerable research concerned with the subjective time scale in animals, mainly the rat and the pigeon. Two procedures are commonly used, temporal differentiation and bisection. Temporal differentiation schedules specify that reinforcing events follow responses of specified durations. Platt (1979), in his review of temporal differentiation performance, showed that under appropriate experimental conditions, the exponent of the power function is virtually 1.00 . In one version of bisection (see Church \& Deluty, 1977), the animal is trained with two durations, one short and one long. Reinforcement is provided for response $R_{S}$ to the short duration and response $R_{L}$ to the long duration. During test, intermediate unreinforced durations are presented. Gibbon (1981) showed that a power function with an exponent of 1.00 provides an excellent description of bisection data and that the analysis was insensitive to the value of the exponent for values as different as .64 and 1.00 .

Our purpose in the present paper is to examine carefully the claim that magnitude estimates of temporal intervals provide support for a nonlinear power function as the psychophysical law. The traditional approach in magnitude estimation has been to collect a few observations from a relatively large number of subjects and to obtain estimates of the power function exponent from data averaged over subjects (see S. S. Stevens, 1971, 1975). Some investigators (e.g., Green \& Luce, 1974; Luce \& Mo, 1965) have cautioned that, given the large between-subject variability in magnitude estimation performance, averaging across subjects may distort the true functional form. Even when temporal interval exponents have been estimated from the responses of individual subjects, they have been based on relatively few observations (Eisler, 1975; Künnapas et al., 1973). We will report data from a study in which a minimum of 70 estimates were obtained for each duration value from each of 11 subjects. The availability of a relatively large number of observations, from each of many subjects, will provide more reliable estimates of the power function exponent. Also, the relationship between exponent size and practice can be examined. Eisler (1976) has suggested that exponents tend to increase with extended practice. In his collection of exponents from numerous studies, he noted that the largest values typically came from experienced subjects, although not all studies showed the effect.

The lognormal model of error is often assumed, explicitly or implicitly, for magnitude estimation data (J. C. Stevens, 1957, 1958; S. S. Stevens, 1971), and S. S. Stevens (1971; Stevens \& Greenbaum, 1966; Stevens \& Guirao, 1962) has stressed the constancy over stimulus values of the coefficient of variation (or of the standard deviation of the logarithms of the magnitude estimates). Generally, lognormality has been evaluated for distributions averaged over 
subjects, and, likewise, variance has been determined by averaging over subjects, thus confounding withinsubject and between-subject variation. Few magnitude estimation studies have examined the distributional characteristics of the data from individual subjects. Those that do, do not support the lognormal model (Jesteadt, Luce, \& Green, 1977; Luce \& Mo, 1965). Studies by Eisler (1962, 1963; Eisler \& Montgomery, 1974; Montgomery \& Eisler, 1974) have shown that the within-subject variance of the $\log$ responses is not homogeneous across stimulus values. None of the magnitude estimation studies of temporal intervals have examined the shape or the variance of the response distributions of individual subjects. This will be done in the present paper.

We will examine both the two-parameter and threeparameter power functions, and we will fit the data using linear and nonlinear estimation procedures. Our purpose is to demonstrate that conclusions derived from magnitude estimation data about the psychophysical law for temporal intervals are very much influenced by the curve-fitting procedure used.

\section{METHOD}

Data from 11 paid subjects, members of the University community, are reported. The subject was seated in a dimly illuminated, sound-attenuated, IAC chamber, approximately $66 \mathrm{~cm}$ from a visual display unit consisting of small indicator bulbs. One bulb was used to mark the beginning of a trial, another to mark the response period.

The durations to be judged were marked by a $1,000-\mathrm{Hz}$ tone at an amplitude of about $70 \mathrm{~dB}$, produced by a Wavetek function generator and presented binaurally over earphones. The presentation and timing of all trial events were controlled on-line by a PDP-8/e computer.

Each trial began with a 500-msec visual warning light, followed $1 \mathrm{sec}$ later by the auditory duration stimulus. The response light was turned on at the end of the duration stimulus and remained on for $6.5 \mathrm{sec}$. The subject recorded his response on a mimeographed sheet during this interval. The next trial began immediately after the response period.

The three experimental conditions, which differed in the values of the 15 duration stimuli, are shown in Table 1. Under the fullrange (FR) condition, stimuli ranged from 20 to 8,100 msec; under the short-range (SR) condition, they ranged from 20 to $300 \mathrm{msec}$; and under the long-range (LR) condition, they ranged from 400 to $8,100 \mathrm{msec}$. The order of the three conditions is indicated in Table 1d for each subject. One subject (S.H.) did not participate under the FR condition.

Table 1a

Symmetry Coefficients: Log Data

\begin{tabular}{|c|c|c|c|c|c|c|c|c|c|c|c|c|c|c|c|}
\hline Ful1 Range & 20 & 50 & 100 & 250 & 500 & 600 & 750 & 1000 & 1300 & 1800 & 2500 & 3300 & 4500 & 6000 & 8100 \\
\hline $\begin{array}{l}\operatorname{MK}(80) \\
\operatorname{PM}(85) \\
\operatorname{MB}(75) \\
\operatorname{CK}(85)\end{array}$ & $\begin{array}{r}0.06 \\
-0.43 \\
8.49 * \\
1.56^{*}\end{array}$ & $\begin{array}{c}-0.23 \\
-0.42 \\
1.64^{*} \\
0.29\end{array}$ & $\begin{array}{c}-0.22 \\
-0.46 \\
2.54^{*} \\
-0.22\end{array}$ & $\begin{array}{l}-0.29 \\
-1.51^{*} \\
-1.46^{\star} \\
0.76^{*}\end{array}$ & $\begin{array}{c}-0.48 \\
-0.00 \\
0.72^{\star} \\
-0.01\end{array}$ & $\begin{array}{c}-0.62 \\
0.66^{\star} \\
-0.09 \\
0.56\end{array}$ & $\begin{array}{r}-0.27 \\
0.62^{\star} \\
-1.86^{\star} \\
0.04\end{array}$ & $\begin{array}{r}-0.73^{\star} \\
0.76^{\star} \\
8.49^{\star} \\
-1.02^{\star}\end{array}$ & $\begin{array}{c}-0.50 \\
1.28^{\star} \\
1.41^{\star} \\
0.03\end{array}$ & $\begin{array}{c}-0.60 \\
0.93^{\star} \\
0.40 \\
0.53\end{array}$ & $\begin{array}{r}-0.57 \\
0.57 \\
0.51 \\
0.76\end{array}$ & $\begin{array}{r}-0.54 \\
0.56 \\
-0.15 \\
0.70^{*}\end{array}$ & $\begin{array}{r}-0.30 \\
0.58 \\
-0.31 \\
0.55\end{array}$ & $\begin{array}{r}-0.24 \\
0.58 \\
-0.01 \\
0.43\end{array}$ & $\begin{array}{c}0.09 \\
0.57 \\
-4.65^{\star} \\
0.63^{*}\end{array}$ \\
\hline $\begin{array}{l}\operatorname{DS}(85) \\
\operatorname{RL}(85) \\
\mathrm{DL}(85)\end{array}$ & $\begin{array}{l}9.06^{*} \\
6.29 \\
4.28^{t}\end{array}$ & $\begin{array}{r}-0.10 \\
0.704 \\
1.07 *\end{array}$ & $\begin{array}{c}-0.96^{\star} \\
-2.11^{\star} \\
0.53\end{array}$ & $\begin{array}{c}-2.46^{4} \\
0.06 \\
0.27\end{array}$ & $\begin{array}{c}-0.81^{*} \\
0.03 \\
-0.71^{\star}\end{array}$ & $\begin{array}{r}-0.98^{*} \\
0.25 \\
-0.22\end{array}$ & $\begin{array}{l}-3.91 * \\
-0.18 \\
-0.74 *\end{array}$ & $\begin{array}{l}-1.49 * \\
-1.10^{*} \\
-0.84^{\star}\end{array}$ & $\begin{array}{r}-0.44 \\
1.93^{\star} \\
-1.26^{\star}\end{array}$ & $\begin{array}{c}0.07 \\
-6.29 * \\
-0.63^{*}\end{array}$ & $\begin{array}{r}1.09 * \\
-9.06 t \\
-1.07 *\end{array}$ & $\begin{array}{l}-0.43 \\
-2.87 \star \\
-0.53\end{array}$ & $\begin{array}{l}-0.06 \\
-0.16 \\
-1.84^{*}\end{array}$ & $\begin{array}{l}-0.67^{\star} \\
-0.69 \hbar \\
-0.50\end{array}$ & $\begin{array}{l}-4.50^{*} \\
-0.21 \\
-0.75^{*}\end{array}$ \\
\hline $\begin{array}{l}\text { ax (85) } \\
\text { CAD(85) } \\
\text { PVO(85) }\end{array}$ & $\begin{array}{l}9.06^{\star} \\
1.83^{\star} \\
5.04^{\star}\end{array}$ & $\begin{array}{r}-6.29 * \\
0.69 * \\
-1.56 t\end{array}$ & $\begin{array}{c}0.39 \\
-0.15 \\
2.76^{*}\end{array}$ & $\begin{array}{l}---- \\
-1.88 * \\
-2.74 k\end{array}$ & $\begin{array}{l}2.78^{\star} \\
0.37 \\
0.05\end{array}$ & $\begin{array}{r}0.28 \\
-0.14 \\
1.44\end{array}$ & $\begin{array}{c}0.01 \\
-1.27 \hbar \\
0.46\end{array}$ & $\begin{array}{l}1.21 * \\
-0.70^{*} \\
-0.24\end{array}$ & $\begin{array}{c}-0.74^{*} \\
-1.00^{*} \\
0.21\end{array}$ & & $\begin{array}{c}-1.05 \\
0.51 \\
0.52\end{array}$ & $\begin{array}{l}-0.29 \\
-0.04 \\
-3.78^{*}\end{array}$ & $\begin{array}{l}0.25 \\
-0.61 \\
-7.27^{\star}\end{array}$ & $\begin{array}{r}-0.52 \\
0.37 \\
0.51\end{array}$ & $\begin{array}{c}-0.19 \\
-1.95^{\star} \\
0.11\end{array}$ \\
\hline Short Range & 20 & 40 & 60 & 80 & 100 & 120 & 140 & 160 & 180 & 200 & 220 & 240 & 260 & 280 & 300 \\
\hline $\begin{array}{l}\operatorname{Hr}(115) \\
\operatorname{PH}(90) \\
\operatorname{NB}(125)\end{array}$ & $\begin{array}{l}2.39 * \\
0.13 \\
2.91^{\star}\end{array}$ & $\begin{array}{r}1.80^{*} \\
-1.39 * \\
3.35 *\end{array}$ & $\begin{array}{r}0.94^{*} \\
-1.08^{*} \\
0.56^{*}\end{array}$ & $\begin{array}{c}0.35 \\
-1.34^{*} \\
-0.92^{*}\end{array}$ & $\begin{array}{r}-0.13 \\
0.29 \\
-2.95\end{array}$ & $\begin{array}{r}-0.40 \\
0.43 \\
-0.10\end{array}$ & $\begin{array}{r}-0.9 \\
0.4 \\
0.4\end{array}$ & $\begin{array}{l}-1.10^{*} \\
-0.26 \\
-0.47\end{array}$ & $\begin{array}{r}-0.9 \\
0.0\end{array}$ & $\begin{array}{c}-0.55^{\star} \\
0.07 \\
-1.08 *\end{array}$ & $\begin{array}{l}61 \\
35 \\
55\end{array}$ & $\begin{array}{c}-0.22 \\
-0.50 \\
0.97^{\star}\end{array}$ & $\begin{array}{l}-0.57^{\star} \\
-0.80^{\star} \\
-0.11\end{array}$ & $\begin{array}{l}-0.81^{\star} \\
-0.75^{\star} \\
-0.18\end{array}$ & $\begin{array}{l}-0 . \\
-0 . \\
-0 .\end{array}$ \\
\hline $\begin{array}{l}C \times(100) \\
\operatorname{DS}(100) \\
\operatorname{RL}(115)\end{array}$ & $\begin{array}{r}0.81^{*} \\
-1.28^{*} \\
1.10^{\star}\end{array}$ & $\begin{array}{l}-0.30 \\
-1.19 \\
-0.44\end{array}$ & $\begin{array}{l}-0.30 \\
-1.42 \\
-0.10\end{array}$ & $\begin{array}{l}-0.23 \\
-1.44^{\star} \\
-1.02\end{array}$ & $\begin{array}{l}-0.13 \\
-1.50^{*} \\
-0.97^{*}\end{array}$ & $\begin{array}{l}-0.0 \\
-1.5 \\
-0.7\end{array}$ & $\begin{array}{l}-0.38 \\
-1.17 \\
-0.80\end{array}$ & $\begin{array}{l}-0.64 * \\
-1.49 * \\
-0.35\end{array}$ & $\begin{array}{l}-0.3 \\
-1.4 \\
-0.6\end{array}$ & $\begin{array}{c}0.04 \\
-1.23^{*} \\
-1.11^{*}\end{array}$ & $\begin{array}{l}-0.24 \\
-1.38^{\star} \\
-0.82^{\star}\end{array}$ & $\begin{array}{l}-0.44 \\
-1.42 \\
-0.80\end{array}$ & $\begin{array}{l}-0.12 \\
-1.42^{\star} \\
-0.81^{*}\end{array}$ & $\begin{array}{l}-1.31 * \\
-1.28 * \\
-2.45^{*}\end{array}$ & $\begin{array}{l}-0.36 \\
-1.32^{*} \\
-5.08^{*}\end{array}$ \\
\hline $\begin{array}{l}\operatorname{DL}(120) \\
\ln (125) \\
\operatorname{CAD}(130) \\
\operatorname{PVO}(115) \\
\text { SH(100) }\end{array}$ & $\begin{array}{c}0.18 \\
3.42 \\
0.52 \\
-1.56\end{array}$ & $\begin{array}{c}0.33 \\
-1.63 * \\
1.69 k \\
0.97 * \\
-0.14\end{array}$ & $\begin{array}{c}0.78^{\circ} \\
0.90^{\circ} \\
0.90^{\star} \\
0.48 \\
-0.16\end{array}$ & $\begin{array}{c}0.17 \\
-0.18 \\
2.39 \\
0.01 \\
-0.59 \hbar\end{array}$ & $\begin{array}{c}-0.19 \\
-0.81 * \\
1.04 * \\
0.16 \\
-0.39\end{array}$ & $\begin{array}{c}-0.33 \\
0.09 \\
1.39 k \\
0.29 \\
-0.20\end{array}$ & $\begin{array}{c}-0.74^{\star} \\
0.78^{*} \\
1.77^{\star} \\
0.38 \\
0.13\end{array}$ & $\begin{array}{c}-0.52 * \\
0.64 * \\
0.77 * \\
-0.05 \\
0.11\end{array}$ & $\begin{array}{r}-1.2 \\
-0.0 \\
0.7 \\
-0.2\end{array}$ & $\begin{array}{c}-1.11^{*} \\
-0.65^{*} \\
0.35 \\
-0.33 \\
-0.23\end{array}$ & $\begin{array}{c}-0.98^{\star} \\
-0.81^{\star} \\
0.02 \\
-0.24 \\
-0.17\end{array}$ & $\begin{array}{l}-1.74^{\star} \\
-0.57^{\star} \\
-0.11 \\
-0.84^{\star} \\
-0.19\end{array}$ & $\begin{array}{r}-1.75^{*} \\
-0.42 \\
0.02 \\
0.40 \\
-0.19\end{array}$ & $\begin{array}{l}-0.61^{*} \\
-0.05 \\
-0.22 \\
-0.71^{*} \\
-0.81^{*}\end{array}$ & $\begin{array}{r}-0.52^{\star} \\
-0.30 \\
-0.25 \\
0.49 \\
-0.39\end{array}$ \\
\hline Long Bange & 400 & 950 & 1500 & 2050 & 2600 & 3150 & 3700 & 4250 & 4800 & 5350 & 5900 & 6450 & 7000 & 7550 & 8100 \\
\hline $\begin{array}{l}\operatorname{LR}(85) \\
\operatorname{PL}(70) \\
\operatorname{MB}(85) \\
\operatorname{CK}(80) \\
\operatorname{Ds}(85) \\
\operatorname{RL}(100) \\
\operatorname{DL}(75) \\
\operatorname{Mx}(70)\end{array}$ & $\begin{array}{r}1.81^{\star} \\
5.66^{\star} \\
-6.09{ }^{\star} \\
-0.35 \\
3.04^{\star} \\
5.51^{\star} \\
-0.95^{\star} \\
2.49^{\star}\end{array}$ & $\begin{array}{l}-0.39 \\
-0.98^{\star} \\
-0.70^{\star} \\
-1.48^{*} \\
-1.05^{\star} \\
0.17 \\
2.10^{*}\end{array}$ & $\begin{array}{c}-0.69 \star \\
-0.47 \\
0.60 \\
-1.30^{\star} \\
-0.78^{\star} \\
2.36 \star \\
-0.35 \\
1.77 \star\end{array}$ & $\begin{array}{l}-0.48 \\
-0.42 \\
-0.83^{\star} \\
-0.28 \\
-0.42 \\
-1.45 \\
-1.52^{\star} \\
1.61^{\star}\end{array}$ & $\begin{array}{c}0.02 \\
-0.24 \\
-1.02 \\
-0.51 \\
-0.39 \\
-0.63^{\star} \\
-0.36 \\
1.65\end{array}$ & $\begin{array}{c}-0.40 \\
0.00 \\
0.66^{\star} \\
-0.47 \\
-0.15 \\
0.58^{\star} \\
-0.27 \\
1.56^{\star}\end{array}$ & $\begin{array}{r}-0.60 \\
-0.35 \\
0.34 \\
-0.48 \\
-0.26 \\
-0.22 \\
-0.67 \star \\
1.67 \star\end{array}$ & $\begin{array}{r}-0.49 \\
-0.35 \\
0.00 \\
-0.42 \\
-0.11 \\
0.29 \\
-0.07 \\
1.89 *\end{array}$ & $\begin{array}{r}-1.20^{\star} \\
-0.25 \\
0.08 \\
-0.22 \\
-0.08 \\
-0.82^{\star} \\
-0.86^{\star} \\
1.58^{\star}\end{array}$ & $\begin{array}{c}-2.15^{\star} \\
-0.69 \\
0.37 \\
-0.36 \\
-0.60 \\
-0.16 \\
-0.88 \\
1.71\end{array}$ & $\begin{array}{c}-0.75^{\star} \\
-0.30 \\
0.02 \\
-0.20 \\
0.02 \\
-1.09 * \\
-0.90^{\star} \\
1.72\end{array}$ & $\begin{array}{l}-2.04 \star \\
-0.64 \\
0.15 \\
-0.47 \\
-2.37 \star \\
-0.19 \\
-0.57 \\
1.69 \star\end{array}$ & $\begin{array}{l}-1.11^{\star} \\
-0.36 \\
0.17 \\
-0.34 \\
-0.10 \\
-0.24 \\
-0.60 \\
1.79\end{array}$ & $\begin{array}{l}-1.79 * \\
-0.34 \\
-1.36 * \\
-0.55 \\
0.37 \\
-2.06 * \\
-0.45 \\
1.65 *\end{array}$ & $\begin{array}{l}-1.78^{\star} \\
-0.27 \\
-3.20^{\star} \\
-0.48 \\
-4.07^{\star} \\
-2.87^{\star} \\
-0.22 \\
1.73^{*}\end{array}$ \\
\hline $\begin{array}{l}1470) \\
C A D(100)\end{array}$ & $\begin{array}{r}2.49 * \\
-2.27 * \\
6.29 *\end{array}$ & $\begin{array}{l}2.10^{*} \\
0.24 \\
1.31^{\star}\end{array}$ & $\begin{array}{c}1.77^{\star} \\
0.30 \\
-0.67 \hbar\end{array}$ & $\begin{array}{l}1.61^{*} \\
0.35 \\
1.95\end{array}$ & $\begin{array}{c}1.65 * \\
0.05 \\
-1.69\end{array}$ & $\begin{array}{c}1.56^{\star} \\
0.42 \\
-1.08^{*}\end{array}$ & $\begin{array}{l}1.67 * \\
-0.45 \\
-0.71 *\end{array}$ & $\begin{array}{r}1.89 * \\
-0.70^{*} \\
1.68^{*}\end{array}$ & $\begin{aligned} & 1.58 \\
&-0.09 \\
&-0.07\end{aligned}$ & $\begin{array}{c}1.71^{\star} \\
0.32 \\
-1.30^{\star}\end{array}$ & $\begin{array}{r}1.724 \\
0.26 \\
-0.39\end{array}$ & $\begin{array}{c}1.69 k \\
0.34 \\
-1.14 k\end{array}$ & $\begin{array}{r}1.79 * \\
0.55 \\
-0.56\end{array}$ & $\begin{array}{l}1.65^{\star} \\
-0.53 \\
-0.71^{\star}\end{array}$ & $\begin{array}{r}1.73^{*} \\
-6.19^{*} \\
-2.20^{*}\end{array}$ \\
\hline $8 \mathrm{H}(80)$ & -1.40 & -0.11 & -0.13 & 0.42 & 0.35 & 0.39 & 0.62 & 0.56 & 0.50 & 0.27 & 0.41 & 0.35 & -0.01 & 0.18 & 0.45 \\
\hline
\end{tabular}

Note-Under the lognormal hypothesis, starred (*) values lie beyond the Ist or 99th percentile of the sampling distribution of $\sqrt{b}$. Dashes (-) are for zero variance conditions. Bracketed numbers indicate the number of observations per subject per stimulus. 
Table 1b

Kurtosis Coefficients: Log Data

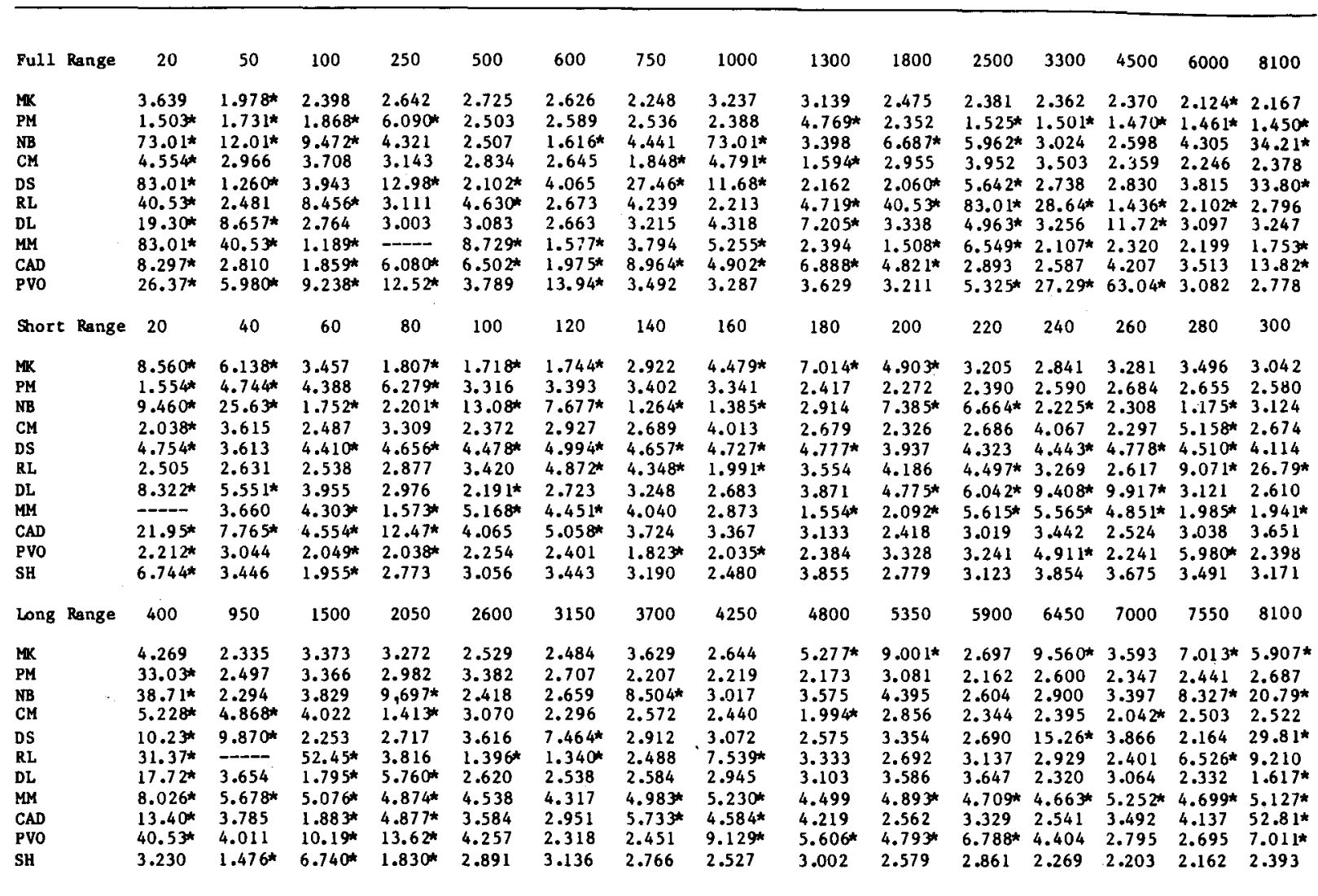

Note-Under the lognormal hypothesis, starred $\left({ }^{*}\right)$ values lie beyond the 1st or 99th percentile of the sampling distribution of $b_{2}$. Dashes (---) are for zero variance conditions.

Table 1c

Sample Variances: Log Data

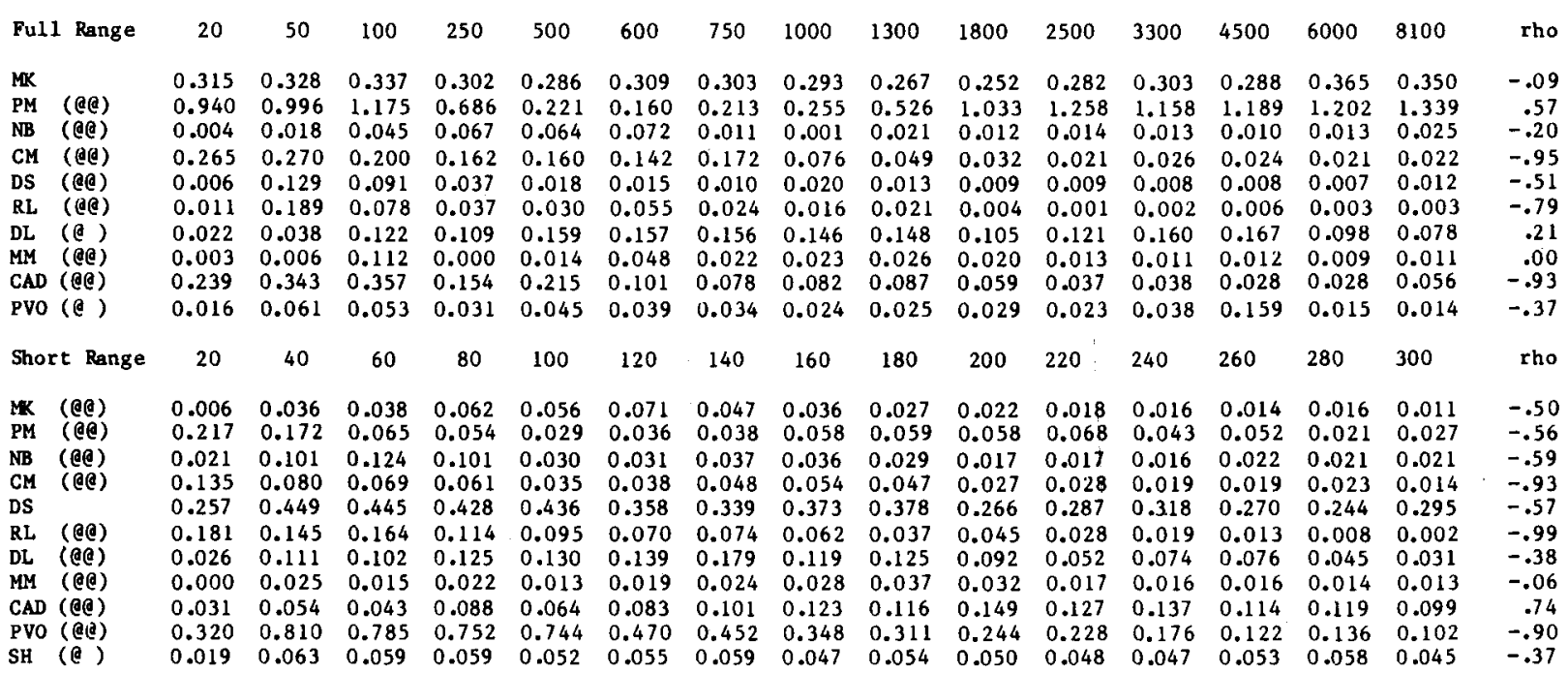


Table 1c continued

$\begin{array}{lllllllllllllllll}\text { Long Range } & 400 & 950 & 1500 & 2050 & 2600 & 3150 & 3700 & 4250 & 4800 & 5350 & 5900 & 6450 & 7000 & 7550 & 8100 & \text { rho } \\ \text { MK (@e) } & 0.066 & 0.051 & 0.094 & 0.053 & 0.055 & 0.048 & 0.023 & 0.038 & 0.042 & 0.059 & 0.021 & 0.023 & 0.034 & 0.021 & 0.020 & -.80 \\ \text { PM (@)) } & 0.013 & 0.097 & 0.097 & 0.080 & 0.077 & 0.088 & 0.070 & 0.084 & 0.097 & 0.081 & 0.076 & 0.072 & 0.090 & 0.069 & 0.072 & -.22 \\ \text { NB (@) } & 0.011 & 0.061 & 0.025 & 0.008 & 0.013 & 0.014 & 0.006 & 0.012 & 0.012 & 0.008 & 0.009 & 0.010 & 0.007 & 0.009 & 0.012 & -.41 \\ \text { CM (@) } & 0.088 & 0.063 & 0.033 & 0.021 & 0.022 & 0.019 & 0.020 & 0.019 & 0.018 & 0.015 & 0.013 & 0.018 & 0.015 & 0.016 & 0.016 & -.89 \\ \text { DS (@e) } & 0.036 & 0.034 & 0.036 & 0.025 & 0.018 & 0.022 & 0.014 & 0.010 & 0.010 & 0.007 & 0.007 & 0.010 & 0.005 & 0.005 & 0.008 & -.91 \\ \text { RL (@e) } & 0.014 & 0.000 & 0.004 & 0.013 & 0.011 & 0.008 & 0.012 & 0.004 & 0.004 & 0.005 & 0.005 & 0.004 & 0.006 & 0.002 & 0.001 & -.45 \\ \text { DL (@e) } & 0.024 & 0.136 & 0.171 & 0.061 & 0.062 & 0.043 & 0.049 & 0.035 & 0.052 & 0.060 & 0.051 & 0.055 & 0.053 & 0.051 & 0.046 & -.23 \\ \text { MM (@e) } & 0.023 & 0.047 & 0.055 & 0.058 & 0.045 & 0.042 & 0.034 & 0.039 & 0.033 & 0.035 & 0.039 & 0.038 & 0.039 & 0.034 & 0.035 & -.36 \\ \text { CAD (@e) } & 0.033 & 0.023 & 0.017 & 0.017 & 0.015 & 0.010 & 0.016 & 0.013 & 0.011 & 0.012 & 0.009 & 0.011 & 0.008 & 0.011 & 0.052 & -.48 \\ \text { PVo (@e) } & 0.011 & 0.027 & 0.016 & 0.014 & 0.006 & 0.007 & 0.009 & 0.011 & 0.005 & 0.004 & 0.006 & 0.005 & 0.004 & 0.004 & 0.002 & -.88 \\ \text { SH (@e) } & 0.139 & 0.115 & 0.051 & 0.057 & 0.092 & 0.104 & 0.102 & 0.118 & 0.113 & 0.125 & 0.121 & 0.117 & 0.143 & 0.107 & 0.113 & .29\end{array}$

Note-@s indicate that these values differ significantly for this subject. Two of them indicate significant differences even if the responses to the four extreme stimuli are excluded from analysis.

Table 1d

Arithmetic Mean Response

\begin{tabular}{lllllllllllllllll}
\hline Ful1 Range & 20 & 50 & 100 & 250 & 500 & 600 & 750 & 1000 & 1300 & 1800 & 2500 & 3300 & 4500 & 6000 & 8100 & \\
MK (1) & 1.083 & 1.530 & 1.880 & 3.059 & 4.281 & 4.744 & 5.706 & 6.625 & 7.756 & 9.394 & 12.35 & 14.89 & 18.64 & 24.79 & 33.01 \\
PM (1) & 0.272 & 0.449 & 0.765 & 1.525 & 2.300 & 2.753 & 3.047 & 3.518 & 6.212 & 13.73 & 21.75 & 26.75 & 37.14 & 51.46 & 73.75 \\
NB (3) & 0.303 & 0.517 & 0.560 & 0.927 & 1.248 & 1.447 & 1.920 & 2.007 & 2.193 & 3.127 & 4.173 & 5.387 & 7.447 & 9.420 & 12.27 \\
CM (1) & 0.156 & 0.333 & 0.491 & 0.661 & 1.194 & 1.341 & 1.606 & 2.094 & 2.612 & 3.435 & 4.306 & 5.671 & 7.365 & 9.482 & 12.79 \\
DS (3) & 1.012 & 1.577 & 2.047 & 2.918 & 3.730 & 3.882 & 3.977 & 4.353 & 4.730 & 5.388 & 6.353 & 7.330 & 8.988 & 10.81 & 13.52 \\
RL (3) & 0.102 & 0.274 & 0.491 & 0.681 & 0.990 & 1.119 & 1.612 & 1.871 & 2.153 & 2.977 & 3.988 & 4.988 & 6.588 & 8.718 & 11.52 \\
DL (3) & 0.105 & 0.217 & 0.320 & 0.559 & 0.998 & 1.162 & 1.211 & 1.507 & 1.986 & 2.459 & 3.166 & 3.860 & 4.978 & 6.260 & 8.155 \\
MM (1) & 0.302 & 0.495 & 0.701 & 1.000 & 2.094 & 2.524 & 3.259 & 4.365 & 6.153 & 8.553 & 11.90 & 15.59 & 21.33 & 28.46 & 37.93 \\
CAD (1) & 0.161 & 0.309 & 0.476 & 0.796 & 1.437 & 1.661 & 1.973 & 2.382 & 3.021 & 4.135 & 5.495 & 7.086 & 9.051 & 11.72 & 15.99 \\
PVO (1) & 0.518 & 0.947 & 1.118 & 1.965 & 2.730 & 3.024 & 3.377 & 4.235 & 5.318 & 6.930 & 9.224 & 11.74 & 15.68 & 20.74 & 28.00
\end{tabular}

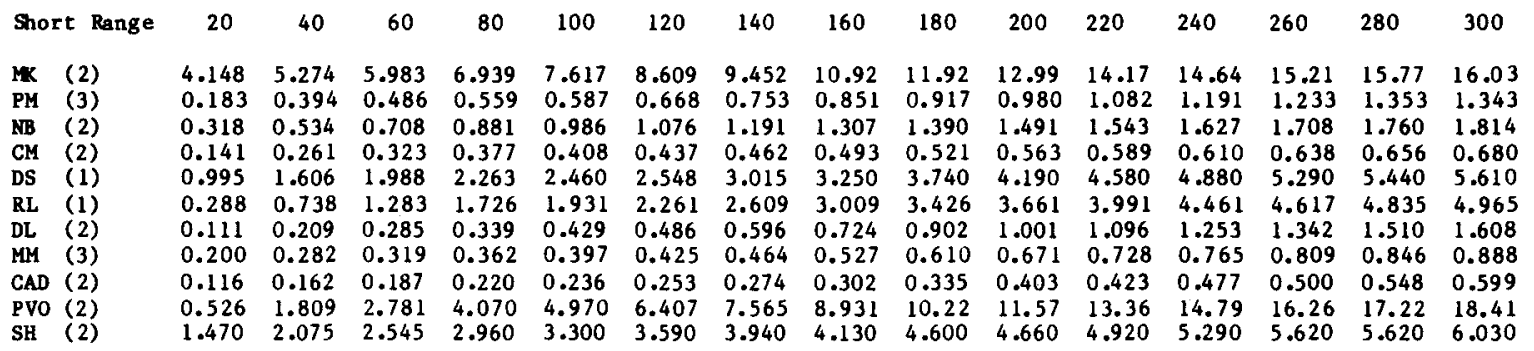

$\begin{array}{lllllllllllllllll}\text { Long Range } & 400 & 950 & 1500 & 2050 & 2600 & 3150 & 3700 & 4250 & 4800 & 5350 & 5900 & 6450 & 7000 & 7550 & 8100 \\ \text { MK (3) } & 5.824 & 14.71 & 22.59 & 27.59 & 31.24 & 35.35 & 39.41 & 41.97 & 45.57 & 47.78 & 51.72 & 54.05 & 54.59 & 57.93 & 58.51 \\ \text { PM (2) } & 1.029 & 1.786 & 2.700 & 3.557 & 4.414 & 5.400 & 6.643 & 7.343 & 8.172 & 9.057 & 10.02 & 10.72 & 11.90 & 12.73 & 13.39 \\ \text { NB (1) } & 0.986 & 1.634 & 2.137 & 2.962 & 3.708 & 4.357 & 5.031 & 5.831 & 6.370 & 7.153 & 7.641 & 8.348 & 8.958 & 9.613 & 10.24 \\ \text { CM (3) } & 1.000 & 1.888 & 2.813 & 3.613 & 4.369 & 5.200 & 5.975 & 6.788 & 7.556 & 8.225 & 9.025 & 9.744 & 10.57 & 11.45 & 12.10 \\ \text { DS (2) } & 1.082 & 2.071 & 2.753 & 3.530 & 4.165 & 4.941 & 5.647 & 6.341 & 7.047 & 7.659 & 8.577 & 9.071 & 9.859 & 10.66 & 11.18 \\ \text { RL (2) } & 1.030 & 2.000 & 3.010 & 3.830 & 4.650 & 5.360 & 5.980 & 7.030 & 7.820 & 8.460 & 9.510 & 10.12 & 10.86 & 11.75 & 11.91 \\ \text { DL (1) } & 2.007 & 4.214 & 7.400 & 10.19 & 12.13 & 14.52 & 17.00 & 19.02 & 21.32 & 22.46 & 24.36 & 26.59 & 28.74 & 29.84 & 32.24 \\ \text { MM (2) } & 2.143 & 4.500 & 7.043 & 9.172 & 11.57 & 13.94 & 15.97 & 18.34 & 20.62 & 22.86 & 25.19 & 27.53 & 29.72 & 31.52 & 33.90 \\ \text { CAD (3) } & 1.960 & 3.280 & 4.590 & 6.010 & 7.380 & 8.850 & 10.26 & 11.65 & 13.05 & 14.52 & 15.74 & 17.47 & 18.79 & 20.10 & 21.11 \\ \text { PVO (3) } & 3.071 & 6.318 & 9.247 & 12.07 & 14.50 & 17.19 & 19.52 & 22.10 & 24.14 & 26.48 & 29.47 & 31.85 & 34.17 & 36.71 & 38.24 \\ \text { SH (1) } & 4.438 & 7.850 & 10.61 & 12.90 & 15.76 & 18.95 & 21.06 & 23.75 & 26.54 & 30.50 & 32.60 & 36.75 & 39.56 & 42.94 & 45.79\end{array}$


The first block of trials under each condition was a practice block, consisting of 30 trials. All other blocks consisted of 75 trials, each duration value occurring five times. There were either three or four blocks per session and six or seven sessions per condition. The number of responses per subject per stimulus duration is listed in Table 1a.'

The instructions, with appropriate modifications, were taken from S. S. Stevens $(1975$, p. 30$)$, and were read by the subject.

\section{Instructions}

At the beginning of the first condition. "You will be presented with a series of tones in irregular order. Your task is to tell how long they are by assigning numbers to them. Call the first tone any number that seems appropriate to you. Do not feel that you should think in terms of seconds. After you have assigned a number to the first tone, assign numbers to the next stimuli in such a way that they reflect your subjective impression. There is no limit to the range of numbers that you may use. You may use whole numbers, decimals, or fractions. Try to make each number match the length as you perceive it.

"Before each tone comes on, a light (the left one) will be turned on briefly, as a warning stimulus. After the tone goes off, the other light (the right one) will come on, and signal the response interval. During this interval, you should write down the number that you assigned to the tone on the paper provided to you.

"On the paper, please complete each column before you start the next one. I have numbered the first 10 places that you should enter a number."

At the beginning of the second and third conditions. "You are moving into a new phase in this experiment, and you will find that the range of stimuli has been changed. During the first block you will be presented with each of the new stimuli at least once. The first block will contain only 30 trials. The next blocks will, as usual, contain 75 trials."

The subjects were not explicitly requested to base their numerical judgments on a comparison with the last preceding stimulus, because Ward $(1971,1973)$ indicates that this is a means of maximizing sequential effects, which we preferred to minimize.

\section{RESULTS AND DISCUSSION}

The magnitude estimates (MEs) from the response sheets were entered into either the PDP-8/e or a Pet computer and stored on disks. Summary statistics based on all responses, excluding the practice block of 30 trials, are shown in Table 1.

\section{The Lognormal Model of Error}

It is a nearly universal practice to analyze log MEs. The average used is the arithmetic mean of the $\log$ responses, the curve-fitting procedure is linear regression in $\log -\log$ coordinates, and tests of fit, if conducted, are in these coordinates. Support for this approach is based largely on the lognormal model of error.

According to the lognormal model (see Cross, 1974), the presentation of a physical stimulus, $\phi$, produces a perceptual or subjective response of variable magnitude, $\psi_{i}$, which is related to $\phi$ by the following psychophysical law:

$$
\psi_{\mathrm{i}}=\phi^{\beta} \varepsilon_{\mathrm{i}} .
$$

The multiplicative error term $\varepsilon_{\mathrm{i}}$ is a random variable to which, for a fixed $\phi$, all variability in $\psi_{i}$ is attributed. According to the model, $\varepsilon_{\mathrm{i}}$ is lognormally distributed and the variance of $\varepsilon_{\mathrm{i}}$ is constant over all values of $\phi$. In a magnitude estimation task, it is assumed that numbers, $R_{i}$, are matched directly to a given $\phi$ and that they are proportional to $\psi_{\mathrm{i}}$. Thus,

$$
\mathrm{R}_{\mathrm{i}}=\alpha \psi_{\mathrm{i}}=\alpha \phi^{\beta} \varepsilon_{\mathrm{i}} .
$$

If $R$ is an appropriately averaged estimate of $\alpha \psi_{i}$, then $R=\alpha \psi$ and the two-parameter power function is written as

$$
\mathbf{R}=\alpha \phi^{\beta} .
$$

If the random variable $\varepsilon_{i}$ is lognormally distributed, then $\log \varepsilon_{\mathrm{i}}$ is normally distributed. The population centrality and variability parameters of $\varepsilon_{i}$ and of $\log \varepsilon_{i}$ are (Johnson \& Kotz, 1970):

$\begin{array}{lcc} & \varepsilon & \log \varepsilon \\ \text { arithmetic mean } & \mathrm{e}^{\mu}+\sigma^{2 / 2} & \mu \\ \text { median } & \mathrm{e}^{\mu} & \mu \\ \text { geometric mean } & \mathrm{e}^{\mu} & \text { undefined } \\ \text { variance } & \mathrm{e}^{2 \mu+\sigma^{2}}\left(\mathrm{e}^{\left.\sigma^{2}-1\right)}\right. & \sigma^{2}\end{array}$

In this notation, for a given $\phi, \alpha \psi=\mathrm{e}^{\mu}$ and $\mu=\log (\alpha \psi)$. Both the geometric mean (GM) and the median are unbiased estimates of $\alpha \psi$, although the GM is more efficient, and therefore, for the two-parameter power function (Equation 3), the appropriate average is the GM. The arithmetic mean (AM) is $\mathrm{e}^{\mu+\sigma^{2 / 2}}$ and is therefore biased upwards in estimating $\mu$.

Since the AM of the $\log$ responses is the $\log \mathrm{GM}$ of the responses, unbiased averaging is most conveniently carried out after $\log$ transformation. Furthermore, since $\log R_{i}=\log \varepsilon_{i}+\beta \log \phi+\log \alpha$, the transform is ideal for least squares analysis. Under the assumptions of the lognormal model of error, log transformation is justified.

To our knowledge, the lognormal model has never been examined for magnitude estimates of temporal intervals. However, along other stimulus dimensions, the model has received general acceptance since it was proposed by J. C. Stevens $(1957,1958)$ for magnitude estimation. J. C. Stevens (1957) asked each of 70 subjects to make one estimate about seven different stimulus values. He found that, for each stimulus value, the distribution of the 70 estimates, when plotted in log-probability coordinates, was "roughly linear" (p. 5), indicating that the "logarithmically transformed estimates are distributed fairly normally" (p. 5). He also found that the GM and the median were very similar (see also S. S. Stevens, Carton, \& 
Shickman, 1958), as would be expected from the model. There have been a few negative reports (Jesteadt et al., 1977; John, 1971; Luce \& Mo, 1965). Given the wide acceptance of the lognormality hypothesis, we were surprised to find that lognormality provides a very poor description of our data. In particular, the skew of the raw data is often negative and the variances of the log responses are not constant across stimulus values.

Lognormality. According to the lognormal model, the expected values for the coefficients of symmetry $\left(\sqrt{\beta_{1}}\right)$ and of kurtosis $\left(\beta_{2}\right)$ are 0 and 3, respectively, for the $\log$ responses. An examination of Tables 1a and $1 b$ suggests that the sample values, $\sqrt{b_{1}}$ and $b_{2}$, often appear to differ from the expected values. The R test (Pearson, D'Agostino, \& Bowman, 1977) was used to determine the significance of these deviations. The critical values were the upper and lower $1 \%$ points of the null distribution of $\sqrt{b_{1}}$ and $b_{2}$ (D'Agostino \& Pearson, 1973), yielding a nominal rejection rate per test of less than .04 (Pearson et al., 1977, p. 234). As an illustration of the rejection rule, for $n=70$, $H_{0}$ is rejected if $\sqrt{b_{1}}$ lies outside the interval $(-.673$, $.673)$ or if $b_{2}$ lies outside $(2.08,4.63)$. Starred $(*)$ values in Tables $1 \mathrm{a}$ and $1 \mathrm{~b}$ are significant by this criterion. Of the 477 distributions (there were three zero-variance distributions), 301 (63\%) are rejected. The rejections are spread across all subjects, all durations, and all ranges. The significance levels were not corrected for multiple testing, because the resulting critical values would have been unrealistically extreme. Some rejections are expected on the basis of chance alone, but $\mathrm{H}_{0}$ is rejected so often that the negative results cannot be accounted for solely on this basis.

This rejection of the hypothesis of normality of the $\log$ responses is consistent with the findings of Jesteadt et al. (1977) and Luce and Mo (1965) for response distributions of individual subjects. John (1971) determined the skew of the individual response distributions but only reported the mean values. His data also rejected lognormality.

Variability. As with lognormality, the confounding of within-subject and between-subject variation has clouded the study of the variability of MEs. When all the responses of all subjects to a stimulus value are pooled for the calculation of the variance, a frequent, though not inevitable, result is a constant variance of the $\log$ responses across stimulus values. If we restrict attention to studies dealing with responses of individual subjects, we find many reports of nonhomogeneity of variance of $\log$ MEs (for example, Eisler, 1962, 1963; Eisler \& Montgomery, 1974; John, 1971; Luce \& Mo, 1965; Montgomery, 1975; Montgomery \& Eisler, 1974; Pradhan \& Hoffman, 1963).

To test the homogeneity of the variances of the log data (Table 1c) for individual subjects, we extended a distribution-free procedure for the two-sample case suggested by Moses (1963; described by Hollander \& Wolfe, 1973). In the two-sample case, each sample is randomly divided into a set of subsamples, the variance of each subsample is estimated, and the two sets of variances compared using the Mann-Whitney $\mathrm{U}$ test. If the variance of one population is larger than that of the other, the subsample variances will also be larger, leading to rejection of the hypothesis of homogeneity by the $U$ test.

The generalization to more than two samples is straightforward. For each subject/condition, each of the 15 distributions was randomly (triple randomization by the computer) subdivided into five subsamples, the variance of each subsample was calculated, and the five estimates per distribution were compared among the 15 distributions using the Kruskal-Wallis test. In 28 of the 32 subject/conditions, indicated by ampersands in Table 1c, homogeneity is rejected (uncorrected $\alpha=.05$ ). Given the evidence of nonhomogeneity, we computed Spearman correlations between stimulus magnitude and the variance of the $\log$ data. (Since the mean responses of the subjects virtually always increased with duration, this is equivalent to correlating response magnitude and variance). The correlations are also listed in Table 1c, and in $\mathbf{2 7}$ of the $\mathbf{3 2}$ cases they are negative. In general, then, variability of the $\log$ responses, for individual subjects, tends to decrease with response magnitude.

Eisler $(1962,1963)$ has noted that the variances of MEs to the largest and smallest stimuli of the range are often too small. To check that end effects did not provide the sole basis for rejection of homogeneity, we excluded the responses to the two largest and two smallest stimuli of the range. The 24 rejections by this test are indicated by a second ampersand in $\mathrm{Ta}$ ble 1c.

In sum, our results do not support the lognormal model for magnitude estimates of temporal intervals. The majority of the individual subject distributions of $\log$ responses deviate from normality, and the variance of the $\log$ responses tends to decrease with increasing stimulus duration.

\section{Averaging}

It is not clear from the above analyses whether the best measure of "average" response is the median, the GM, or the AM. Since the lognormal model fails to describe the data, we are assured of neither the optimal properties of the GM nor the bias of the AM.

We have both positively and negatively skewed distributions (see Table 1a). Usually, when the direction of skew is unpredictable or when one is in doubt about the appropriate measure of central tendency, the median has been the recommended measure (S. S. Stevens, 1955, 1971). In fact, until J. C. Stevens (1957, 
1958) reported evidence for lognormality, S. S. Stevens advocated and reported medians. However, because of the discreteness of our response distributions, the median will not do. Most of our subjects used relatively few distinct responses to cover a stimulus range. Nearly $40 \%$ of the numbers used, across subjects, conditions, and stimuli, were $.5,1,2,3,4$, or 5. As a result, there are extensive ties in the data. The modal response to a stimulus is often used on more than $50 \%$ of the trials, and is thus the median. This mode-median may stay constant across a number of stimulus values, even though the response distributions are clearly shifting. Others have also commented on the discreteness of MEs (for example, Green \& Luce, 1974; S. S. Stevens et al., 1958).

A variety of arguments which do not depend on the lognormal model have been used to support the GM as the most appropriate average for MEs. Marks (1974) argues that the GM is less sensitive to outlying (deviant) response values than the $\mathrm{AM}$, and is therefore preferable. However, this argument is reasonable only for positively skewed distributions. Since the GM is always less than or equal to the AM (Kendall \& Stuart, 1977), it is even more sensitive to small outliers than the AM and so would be inappropriate for our negatively skewed distributions. A second argument is based on J. C. Stevens's $(1957,1958)$ finding that, averaged over subjects, log GMs were very similar to $\log$ medians. Since the median would be the average of choice if discreteness were not a problem, the GM should be used if it is closer to the median than the AM is. We compared the GMs, AMs, and medians of the present data on a within-subject basis, and found that, in $231(48 \%)$ of the 480 cases, the AM is closer to the median than the GM. Others (for example, Eisler, 1962; Montgomery, 1975) have also noted that the AM did not deviate systematically from the median in their data.

Since the lognormal model fails for our data, and since the AM and the GM estimate the median about as well, there is little positive ground for using the GM. Also, given the bias of the GM for negatively skewed distributions, of which there are many, the GM is inappropriate, if better than the median. For these reasons, we decided to use the AM. ${ }^{2}$ It is of interest to note that Eisler (1975) also reported AMs.

\section{The Psychophysical Function}

In none of the reported studies of magnitude estimates of temporal intervals was there any attempt to compare the goodness-of-fit of the power function with that of a linear function. With exponents averaging about .90 , it would not be surprising to find that the linear function also provides a good description of magnitude estimation data. Since Church and Deluty (1977) and Getty (1975) proposed a logarithmic psychophysical function for temporal intervals, we examined that possibility as well.
For each subject, the AM of all magnitude estimates, excluding the practice block, are shown in Table 1d for each duration value under each stimulus range. Least squares estimates of the intercept, $\alpha$, and the slope, $\beta$, were obtained for the linear function

$$
\mathbf{R}_{\mathrm{AM}}=\alpha+\beta \phi,
$$

for the logarithmic function

$$
\mathbf{R}_{\mathrm{AM}}=\alpha+\beta \log _{\mathrm{e}} \phi,
$$

and for the logarithmic transformation of the twoparameter power function (Equation 3)

$$
\log \mathbf{R}_{\mathrm{AM}}=\log _{e} \alpha+\beta \log _{e} \phi,
$$

\begin{tabular}{|c|c|c|c|c|}
\hline Subject & Column 1 & Column 2 & Column 3 & Column 4 \\
\hline \multicolumn{5}{|c|}{ Full Range } \\
\hline M.K. & .685 & .996 & .977 & .992 \\
\hline P.M. & .568 & .992 & .955 & .996 \\
\hline N.B. & .652 & .998 & .963 & .996 \\
\hline C.M. & .667 & .998 & .987 & .999 \\
\hline D.S. & .784 & .970 & .983 & .975 \\
\hline R.L. & .662 & .999 & .987 & .998 \\
\hline D.L. & .710 & .992 & .997 & .999 \\
\hline M.M. & .626 & 1.000 & .973 & 1.000 \\
\hline C.A.D. & .664 & .998 & .993 & .999 \\
\hline P.V.O. & .644 & 1.000 & .973 & .997 \\
\hline \multicolumn{5}{|c|}{ Short Range } \\
\hline M.K. & .891 & .989 & .968 & .983 \\
\hline P.M. & .911 & .988 & .983 & .989 \\
\hline N.B. & .969 & .967 & .995 & .997 \\
\hline C.M. & .978 & .952 & .978 & .992 \\
\hline D.S. & .875 & .990 & .978 & .982 \\
\hline R.L. & .924 & .990 & .986 & .994 \\
\hline D.L. & .813 & .987 & .984 & .995 \\
\hline M.M. & .864 & .992 & .964 & .976 \\
\hline C.A.D. & .807 & .978 & .941 & .959 \\
\hline P.V.O. & .855 & .997 & .994 & .999 \\
\hline S.H. & .948 & .982 & .998 & .997 \\
\hline \multicolumn{5}{|c|}{ Long Range } \\
\hline M.K. & .971 & .949 & .974 & .990 \\
\hline P.M. & .859 & .999 & .994 & .999 \\
\hline N.B. & .866 & .999 & .991 & .999 \\
\hline C.M. & .873 & .999 & .999 & .999 \\
\hline D.S. & .873 & .999 & .997 & .998 \\
\hline R.L. & .882 & .997 & .999 & .998 \\
\hline D.L. & .903 & .993 & .997 & .998 \\
\hline M.M. & .867 & 1.000 & 1.000 & 1.000 \\
\hline C.A.D. & .858 & 1.000 & .992 & .999 \\
\hline P.V.O. & .884 & .998 & 1.000 & .999 \\
\hline S.H. & .841 & .998 & .990 & .995 \\
\hline Mean & .818 & .990 & .984 & .993 \\
\hline
\end{tabular}

Table 2

Proportion of Variance Accounted for by Various Functions

Note-Columns list the proportion of variance accounted for by the following functions: (1) log (Equation 5), (2) linear (Equation 4). (3) transformed two-parameter power (Equation 6), and (4) two-parameter power (Equation 3). 
Table 3

Estimates of the Power Function Exponent for Each Subject Under Each Condition

\begin{tabular}{|c|c|c|c|}
\hline Subject & Column 1 & Column 2 & Column 3 \\
\hline \multicolumn{4}{|c|}{ Full Range } \\
\hline M.K. & .57 & .78 & .86 \\
\hline P.M. & .97 & 1.17 & 1.13 \\
\hline N.B. & .61 & .87 & .95 \\
\hline C.M. & .72 & .88 & .92 \\
\hline D.S. & .40 & .49 & .60 \\
\hline R.L. & .75 & .89 & .93 \\
\hline D.L. & .71 & .79 & .81 \\
\hline M.M. & .84 & 1.00 & 1.00 \\
\hline C.A.D. & .76 & .89 & .93 \\
\hline P.V.O. & .65 & .90 & 1.00 \\
\hline \multicolumn{4}{|c|}{ Short Range } \\
\hline M.K. & .55 & .62 & .82 \\
\hline P.M. & .69 & .71 & .82 \\
\hline N.B. & .63 & .59 & .53 \\
\hline C.M. & .53 & .49 & .43 \\
\hline D.S. & .64 & .73 & 1.04 \\
\hline R.L. & 1.01 & .88 & .79 \\
\hline D.L. & 1.01 & 1.20 & 1.47 \\
\hline M.M. & .57 & .67 & 1.12 \\
\hline C.A.D. & .59 & .78 & 2.60 \\
\hline P.V.O. & 1.26 & 1.18 & 1.13 \\
\hline S.H. & .52 & .53 & .56 \\
\hline \multicolumn{4}{|c|}{ Long Range } \\
\hline M.K. & .72 & .60 & .52 \\
\hline P.M. & .89 & .95 & .98 \\
\hline N.B. & .82 & .89 & .95 \\
\hline C.M. & .84 & .88 & .93 \\
\hline D.S. & .78 & .85 & .93 \\
\hline R.L. & .83 & .85 & .88 \\
\hline D.L. & .92 & .85 & .80 \\
\hline M.M. & .93 & .95 & .96 \\
\hline C.A.D. & .83 & .91 & 1.00 \\
\hline P.V.O. & .84 & .86 & .88 \\
\hline S.H. & .79 & .92 & 1.15 \\
\hline
\end{tabular}

Note-Columns list the exponent for the following functions: (1) log-transformed two-parameter (Equation 6), (2) twoparameter (Equation 3), and (3) three-parameter (Equation 7).

where $\mathbf{R}_{\mathrm{AM}}$ is the $\mathrm{AM}$ and $\phi$ represents stimulus duration. In Equation 6 , the slope $\beta$ provides an estimate of the power function exponent.

The proportion of variance of the means accounted for $\left(r^{2}\right)$ by each of the three equations is given in the first three columns of Table 2, and the power function exponent $\beta$ estimated by Equation 6 is shown in the first column of Table 3 .

The logarithmic function (Equation 5) provides a poor description of the data. In terms of $r^{2}$, it gives the worst fit, often strikingly so, in 29 of the 32 cases, with a mean $r^{2}$ of only .818 . This accords with the common claim (for example, S. S. Stevens, 1975) that a logarithmic function is not a satisfactory representation of results obtained from direct scaling experiments.

The description of the data provided by the $\log$ transformed power function (Equation 6) is, as expected, far more satisfactory. The mean $r^{2}$ is .984 . Of the 32 exponents, 29 are less than unity, and the median (mean) is .76 (.76).

Given the clear deviation of the slope from unity in $\log$-log coordinates, it is somewhat surprising that the linear function (Equation 4) fits the data so well. The mean $r^{2}$ is .990 . In 21 of the 32 cases $(66 \%), r^{2}$ for the linear function is higher than $r^{2}$ for the log$\log$ power function, and in two cases it is equal. This includes many of the cases in which extreme nonlinearity is indicated by the $\log -\log$ power function exponent. For example, the linear function describes 8 of the 12 sets of data better than the log-log power function when the estimated exponent is less than $.70 .^{3}$

Eisler (1976) has suggested that exponents tend to increase with extended practice in a magnitude estimation task. In his collection of exponents from numerous studies, he noted that the largest values typically came from experienced subjects, although not all such studies showed the effect. In order to assess the role of practice on the performance of our subjects, we examined the data from each subject's first condition, block by block. Using Equation 6, least square estimates of the log-log power function exponent were obtained for each block. Rank-order correlations, $r_{s}$, between block and exponent size are shown in Table 4. Also given are the exponents based on the practice block ( 30 trials), the first block (75 trials), and the final block (75 trials). The median (mean) exponent of the last block is $.78(.74)$, which is less than the median (mean) of the practice block, which is .86 (.89). The correlations between block and exponent size suggest that little can be said about practice for the average subject. While there are trends, these are decreasing as well as increasing, depending on subject and condition. The excellent fit of the linear function to our data cannot be attributed simply to the extensive experience of our subjects.

Table 4

Exponents Based on the Log-Transformed Function (Equation 6) for Individual Blocks of Trials

\begin{tabular}{|c|c|c|c|c|}
\hline \multirow[b]{2}{*}{ Subject } & \multicolumn{3}{|c|}{ Block } & \multirow[b]{2}{*}{ rS } \\
\hline & Practice & First & Last & \\
\hline \multicolumn{5}{|c|}{ Full Range } \\
\hline M.K. & .86 & .59 & .48 & -.337 \\
\hline P.M. & 1.35 & 1.51 & .61 & -.850 \\
\hline C.M. & .75 & .73 & .82 & .689 \\
\hline M.M. & .74 & .79 & .81 & .326 \\
\hline P.V.O. & .88 & .68 & .62 & -.391 \\
\hline C.A.D. & .59 & .74 & .78 & .147 \\
\hline \multicolumn{5}{|c|}{ Short Range } \\
\hline D.S. & .83 & .81 & .72 & .068 \\
\hline R.L. & .83 & 1.22 & .99 & -.547 \\
\hline \multicolumn{5}{|c|}{ Long Range } \\
\hline N.B. & .86 & .87 & .80 & -.676 \\
\hline D.L. & 1.02 & 1.02 & .83 & -.338 \\
\hline S.H. & 1.08 & 1.16 & .69 & -.858 \\
\hline
\end{tabular}


The FR data from one subject (P.V.O.) are shown in log-log coordinates in Figure $1 \mathrm{a}$ and in linear coordinates in Figure $1 \mathrm{~b}$. The dashed line in Figure la is the $\log -\log$ power function (Equation 6), and the solid curve is the linear function (Equation 4) after transformation to $\log -\log$ coordinates. While the fit of the log-log power function is good, in the sense that it accounts for $97 \%$ of the variance of the log AMs, the transformed linear function provides an even better description, accounting for $98 \%$ of the variance. This is the case for 10 of the 32 subject/ conditions. The solid line in Figure $1 \mathrm{~b}$ is the linear function, which accounts for virtually all of the variance. The dashed curve is the log-log power function, transformed back to linear coordinates. This provides a very poor description of the data, especially for the longer durations, accounting for only $91 \%$ of the variance. In 24 of the 32 subject/conditions, the linear function fits the raw data as well as or better
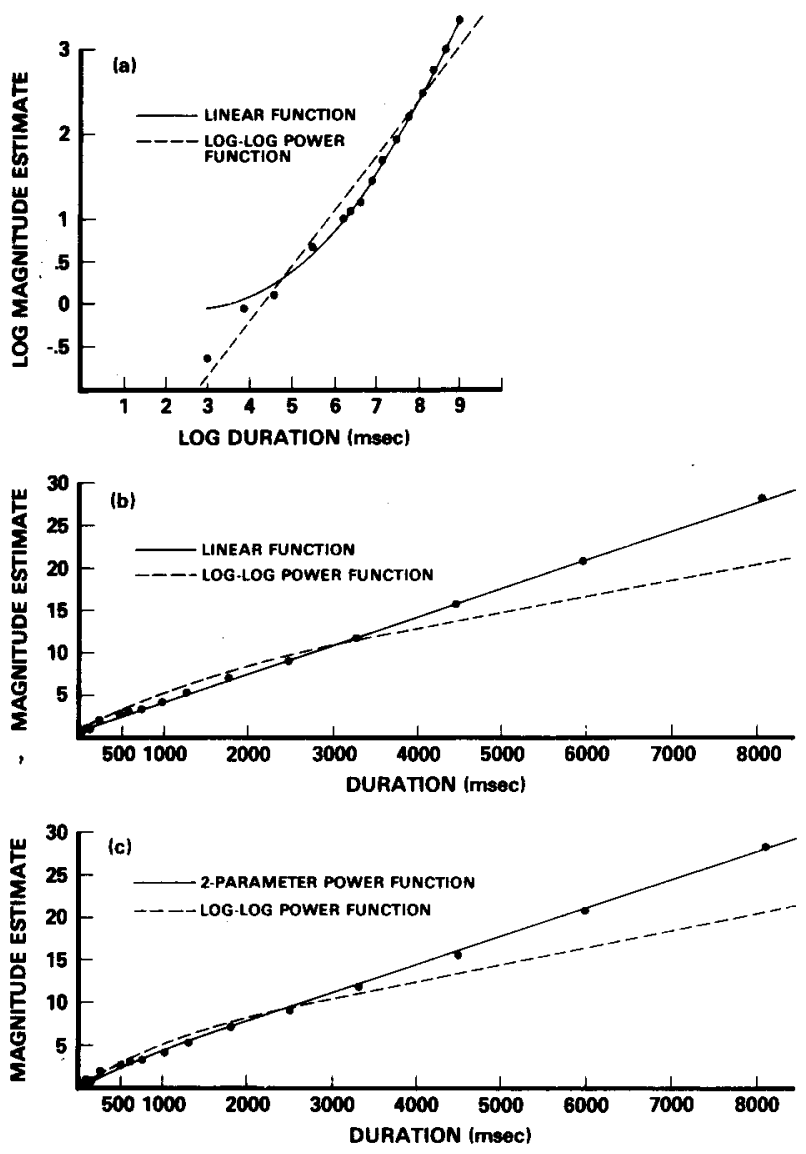

Figure 1. Magnitude estimates for one subject (PVO) under the FR condition are shown as a function of duration in $\log -\log$ coordinates in (a) and in linear coordinates in (b) and (c). In (a) the dashed line is the $\log -\log$ power function and the solid curve is the linear function transformed to $\log$ coordinates. In (b) the solid line is the linear function and the dashed curve is the log-log power function transformed to linear coordinates. In (c) the solid curve is the two-parameter power function and the dashed curve is the log-log power function transformed to linear coordinates. than the $\log -\log$ power function transformed back to linear coordinates. Thus, despite the small exponent estimated for this subject $(\beta=.65)$, which should indicate severe nonlinearity, the linear function provides an excellent description of P.V.O.'s FR data.

A visual inspection of the data, plotted in log-log coordinates, reveals many functions which appear curved. Curved functions were also observed by Eisler (1975) and Michon (1967) for their temporal interval magnitude estimation data plotted in log-log coordinates. To handle the curvature, they fit two linear $\log -\log$ segments to their data. Michon (1967) allowed both the slope and the intercept of the two lines to be different, while Eisler (1975) allowed only the intercept and the location of the point of intersection (the breakpoint) to vary. Using least squares estimation, we fit, in log-log coordinates, segmented twoparameter power functions to our data by an iterative scheme (Bogartz, 1968). The values of $\beta$ and $\alpha$ were free to vary across segments. The location of the breakpoint was varied from the third smallest to the third largest duration value. That duration value yielding the smallest total sum of squared deviations from the two lines, the breakpoint, is shown in Table 5 along with the slopes of the lower and upper segments. The trend in these data is the same as that of Michon (1967), who found that the average lower exponent (.60) was less than the average upper exponent (1.10). In the present experiment, the median (mean) exponent is .69 (.71) for the short-duration part of the range and $.87(.86)$ for the long-duration part of the range. These medians (means) are representative in that 25 of the 32 subject/conditions showed this pattern.

Since there are five free parameters, it is not surprising that the segmented log-log function provides an excellent description of the data. However, even though the fits are excellent, it is not at all clear what interpretation to place on the analysis, given that there is no between-subject consistency in the value of the breakpoint or any sensible relationship among the breakpoint locations for the different ranges. Eisler (1981a) also notes that he does not have a convincing theory for the breakpoints.

Most analyses concerned with the two-parameter power function have used least squares estimation in log-log coordinates (Equation 6) to obtain an estimate of the exponent. Computer programs that deal with nonlinear estimation are now readily available (for example, Bard, 1974; Beck \& Arnold, 1977; Chambers, 1977; Daniel \& Wood, 1971). We reanalyzed the data to obtain estimates of the exponent $\beta$ of the two-parameter power function (Equation 3) based on nonlinear least squares. The curve-fitting program used was a standard iterative, nonlinear least squares program modified for our computer system. ${ }^{4}$ The proportion of the variance accounted for is shown in the last column of Table 2 and the obtained exponents are listed in the second column 
Table 5

Estimates of the Lower and Upper Exponents for the Segmented Log-Log Power Function

\begin{tabular}{|c|c|c|c|}
\hline \multirow[b]{2}{*}{ Subject } & \multicolumn{2}{|c|}{ Segment } & \multirow{2}{*}{$\begin{array}{l}\text { Break- } \\
\text { point }\end{array}$} \\
\hline & Lower & Upper & \\
\hline \multicolumn{4}{|c|}{ Full Range } \\
\hline M.K. & .44 & .72 & 600 \\
\hline P.M. & .71 & 1.25 & 1300 \\
\hline N.B. & .48 & .94 & 1300 \\
\hline C.M. & .56 & .84 & 250 \\
\hline D.S. & .36 & .64 & 2500 \\
\hline R.L. & .77 & .83 & 250 \\
\hline D.L. & .67 & .78 & 1000 \\
\hline M.M. & .48 & 1.05 & 250 \\
\hline C.A.D. & .64 & .86 & 250 \\
\hline P.V.O. & .51 & .88 & 750 \\
\hline \multicolumn{4}{|c|}{ Short Range } \\
\hline M.K. & .37 & .72 & 100 \\
\hline P.M. & .93 & .68 & 60 \\
\hline N.B. & .73 & .56 & 80 \\
\hline C.M. & .77 & .46 & 60 \\
\hline D.S. & .56 & .84 & 100 \\
\hline R.L. & 1.35 & .87 & 60 \\
\hline D.L. & .82 & 1.30 & 120 \\
\hline M.M. & .42 & .86 & 140 \\
\hline C.A.D. & .42 & 1.06 & 140 \\
\hline P.V.O. & 1.54 & 1.19 & 60 \\
\hline S.H. & .51 & .61 & 220 \\
\hline \multicolumn{4}{|c|}{ Long Range } \\
\hline M.K. & 1.03 & .57 & 1500 \\
\hline P.M. & .72 & .96 & 1500 \\
\hline N.B. & .58 & .92 & 1500 \\
\hline C.M. & .79 & .89 & 2600 \\
\hline D.S. & .72 & .87 & 2600 \\
\hline R.L. & .81 & .89 & 3150 \\
\hline D.L. & .97 & .86 & 1500 \\
\hline M.M. & .90 & .95 & 2050 \\
\hline C.A.D. & .64 & .92 & 1500 \\
\hline P.V.O. & .83 & .89 & 5350 \\
\hline S.H. & .67 & .95 & 2600 \\
\hline
\end{tabular}

Note-The value of the breakpoint is given in milliseconds.

in Table 3 . In 26 of the 32 cases (81\%), the proportion of the variance accounted for is higher than it is for the log-log transformation (Equation 6), and in two cases it is equal. The median (mean) exponent is $.87(.83)$ compared with $.76(.76)$ for the log-log transformation (Equation 6). In 25 of the 32 cases, the exponents estimated from Equation 3 were closer to 1.00 than those estimated using the $\log -\log$ transformation (Equation 6). Although the exponents derived from the two curve-fitting procedures differ in value, they are significantly correlated $(r=.93, .91$, and .68 for FR, SR, and LR, respectively).

In Figure 1c, P.V.O.'s FR data are plotted in linear coordinates. The solid curve represents the power function based on nonlinear estimation (Equation 3), and the dashed curve is the function obtained from $\log$-log transformation (Equation 6) and then plotted in linear coordinates. The exponent values estimated by the two curve-fitting procedures are quite differ- ent, .90 for Equation 3 and .65 for Equation 6, and it is clear that Equation 3 provides a much better description of the data.

In terms of proportion of the variance accounted for, the two-parameter power function based on nonlinear estimation and the linear function (Equation 4) provide equivalent accounts of the data. One difference between the two functions is that the predicted response to a zero-duration stimulus is fixed at zero by the power but not by the linear function. If the intercept is not really zero, and it does not look to be in many graphs of the raw data, then the power function exponent will be distorted. The following threeparameter power function

$$
\mathbf{R}_{\mathrm{AM}}=\alpha\left(\phi-\phi_{0}\right)^{\beta}
$$

was fit to the data using nonlinear least squares. As is to be expected, the function accounts for almost all of the variance of the data. The exponents are listed in the last column of Table 3. In general, they are larger than those for the two-parameter function (Equation 3). The median (mean) exponent is .93 (.96). ${ }^{5}$ Although the exponents derived from the twoparameter function (Equation 3) and from the threeparameter function (Equation 7) differ, they are correlated $(r=.98, .43$, and .90 for $F R, S R$, and $L R$, respectively; if C.A.D.'s data are omitted, the $r$ value for $S R$ is .81).

Typically, $\phi_{0}$ in Equation 7 has been interpreted as a threshold parameter (Marks \& J. C. Stevens, 1968; S. S. Stevens, 1961), although Eisler (1963b, 1981a, 1981b) has speculated about alternative interpretations. A number of investigators have reported negative estimates (for example, Eisler, 1962; Mashhour \& Hosman, 1968; Rule, Laye, \& Curtis, 1974). For our data, of the 32 subject/conditions there are 24 negative "thresholds," casting doubt on a threshold explanation.

It is clear from Table 3 that within each stimulus range there is considerable intersubject variability among the exponents of the power function, especially in the SR condition. Intersubject variability in exponent values is common in magnitude estimation. For S. S. Stevens (1971), the observed variability is what one expects in psychophysical experiments, and one remedy he suggested was appropriate averaging over subjects. We have not averaged across subjects because we agree with investigators (for example, Green \& Luce, 1974; Luce \& Mo, 1965) who have argued that averaging may distort the true functional form. As an example, for our data the SR exponent estimated from the $\log$ transformed function (Equation 6) fit to the AM over subjects is .53. The distribution of the 11 individual exponents for SR (Table 3) is bimodal. Of the 11 exponents, 9 are larger than .53 and 1 is equal to .53 .

We examined the data from the 10 subjects who 
participated under all three conditions to determine whether exponent size depended on the set of duration values. The Friedman test indicated that the distributions of exponents did not differ significantly across the three duration ranges. This was the case for each equation (Equations 3, 6, and 7). In fact, for the three-parameter function (Equation 7), the median exponent is .93 for each range.

In sum, on average, the exponent estimated from the $\log$ transformed power function (Equation 6) is less than 1.00. The power function (Equation 3) based on nonlinear estimation provides a better description of the data and yields estimates of the exponent which are closer to 1.00 . Adding a third parameter to the power function (Equation 7) brings the average exponent very close to 1.00 . The fit of the linear function (Equation 4) to the data is just as good as the fit of the two-parameter power function obtained from nonlinear estimation (Equation 3) and better than the fit obtained using linear least squares in $\log$ - $\log$ coordinates (Equation 6).

\section{CONCLUDING COMMENTS}

For magnitude estimates of temporal intervals, the lognormal model of error does not describe the response distributions of individual subjects. Many of the distributions are negatively skewed, and, in general, the variance of the distributions of $\log$ responses decreases as stimulus duration increases. A power function provides an excellent description of the judgments of individual subjects. In terms of the proportion of the variance accounted for, the two-parameter function, obtained using nonlinear estimation, describes the data better than the function obtained using linear least squares in log-log coordinates and yields exponent estimates that are closer to 1.00 . Adding a third parameter to the function results in exponent estimates that are very close to 1.00 . The small deviation from unity might be attributable to "bias" effects. Cross (1973), Green and Luce (1974; Green, Luce, \& Duncan, 1977; Jesteadt et al., 1977), and Ward $(1971,1973,1979)$ have found sequential effects in their ME data. The overriding effect is assimilation, which leads to underestimation of the power function exponent. Green and Luce (Note 5) have performed the standard Green-Luce analysis on our data. Their analysis indicates assimilation, although the effect is smaller than that observed with magnitude estimates of loudness. Regression is another biasing factor in magnitude estimation. According to S. S. Stevens $(1957,1971,1975$; S. S. Stevens \& Greenbaum, 1966), the observer tends to shorten the range of whichever variable he controls. Thus, in magnitude estimation the response scale is typically constricted, leading to underestimation of the exponent.
Our analyses clearly demonstrate that the value of the power function exponent derived from magnitude estimation data depends upon the curve-fitting procedure used. Our results also indicate that a linear function describes the data as well as the two-parameter power function obtained from nonlinear estimation. Magnitude estimation data do not provide compelling evidence against a linear psychophysical function for time.

\section{REFERENCE NOTES}

1. Eisler, H. A note on treatment of ratio setting data for constructing psychological scales (Tech. Rep. 54). Stockholm: University of Stockholm, 1958.

2. Ekman, G. Subjective power functions and the method of fractionation (Tech. Rep. 34). Stockholm: University of Stockholm, 1956.

3. Ekman, G., \& Frankenhauser, M. Subjective time scales (Tech. Rep. 49). Stockholm: University of Stockholm, 1957.

4. Kristofferson, A. B. Personal communiation, 1981.

5. Green, D. M. Personal communication, 1979.

\section{REFERENCES}

Altuan, L. G. The time-order error in judgments of duration. Canadian Journal of Psychology, 1977, 31, 24-31.

Allan, L. G. Comments on current ratio-setting models for time perception. Perception \& Psychophysics, 1978, 24, 444-450.

Allan, L. G. The perception of time. Perception \& Psychophysics, 1979, 26, 340-354.

Allan, L. G., \& Kristorferson, A. B. Psychophysical theories of duration discrimination. Perception \& Psychophysics, 1974, 16, 26-34.

Allan, L. G., Kristofferson, A. B., \& Wiens, E. W. Duration discrimination of brief light flashes. Perception \& Psychophysics, 1971, 9, 327-334.

ANDERson, N. H. Note on functional measurement and data analysis. Perception \& Psychophysics, 1977, 21, 201-215.

BARD, Y. Nonlinear parameter estimation. New York: Academic Press, 1974.

Beck, J. V., \& ARnold, K. J. Parameter estimation in engineering and science. New York: Wiley, 1977.

Birnbaum, M. H. The devil rides again: Correlation as an index of fit. Psychological Bulletin, 1973, 79, 239-242.

Blankenship, D. A., \& Anderson, N. H. Subjective duration: A functional measurement analysis. Perception \& Psychophysics, 1976, 20, 168-172.

Bobro, D. J., Thompson, J. G., \& Schiffman, H. R. The perception of brief temporal intervals: Power functions for auditory and visual stimulus intervals. Perception, 1977, 6, 703-709.

BooArtz, R. S. A least squares method for fitting intercepting line segments to a set of data points. Psychological Bulletin, 1968, 70, 749-755.

Chambers, J. M. Computational methods for data analysis. New York: Wiley, 1977.

Church, R. M., \& Deluty, M. Z. Bisection of temporal intervals. Journal of Experimental Psychology: Animal Behavior Processes, 1977, 3, 216-228.

Creelman, C. D. Human discrimination of auditory duration. Journal of the Acoustical Society of America, 1962, 34, 582-593.

Cross, D. V. Sequential dependencies and regression in psychophysical judgments. Perception \& Psychophysics, 1973, 14, 547-552.

CRoss, D. V. Some technical notes on psychophysical scaling. In H. R. Moskowitz, B. Scharf, \& J. C. Stevens (Eds.), Sensation and measurement. Dordrecht, Holland: D. Reidel, 1974. 
Curtis, D. W., \& Rule, S. J. Judgment of duration relations: Simultaneous and sequential presentation. Perception \& Psychophysics, 1977, 22, 578-584.

D'Agostino, R. B., \& Pearson, E. S. Tests for departure from normality. Fuller empirical results for the distributions of $b_{2}$ and $b_{1}$. Biometrika, 1973, 60, 613-622.

Danizl, C., \& Wood, F. S. Fitting equations to data. New York: Wiley, 1971.

Ersler, H. Empirical test of a model relating magnitude and category scales. Scandinavian Journal of Psychology, 1962, 3, 88-96.

Ersuen, H. Magnitude scales, category scales, and Fechnerian integration. Psychological Review, 1963, 70, 243-253. (a)

Eisuen, H. Possible implications of a non-constant subjective zero in the psychophysical power function. Perceptual \& Motor Skills, 1963, 16, 778. (b)

Erslen, H. The derivation of Stevens' psychophysical power law. In H. R. Moskowitz, B. Scharf, \& J. C. Stevens (Eds.), Sensation and measurement. Dordrecht, Holland: D. Reidel, 1974.

EIsLer, H. Subjective duration and psychophysics. Psychological Review, 1975, 82, 429-450.

ErsleR, H. Experiments on subjective duration 1868-1975: A collection of power function exponents. Psychological Bulletin, 1976, 83, 1154-1171.

EIsLer, H. Applicability of the parallel-clock model to duration discrimination. Perception \& Psychophysics, 1981, 29, 225233. (a)

Ersle R, H. The parallel-clock model: Replies to critics and criticisms. Perception \& Psychophysics, 1981, 29, 516-520. (b)

EISLER, H., \& Montgomery, H. On theoretical and realizable ideal conditions in psychophysics: Magnitude and category scales and their relation. Perception \& Psychophysics, 1974, 16, 157-168.

Frankenhaeuger, M. Subjective time as affected by gravitational stress. Scandinavian Journal of Psychology, 1960, 1, 1-6.

GeTTy, D. J. Discrimination of short temporal intervals. Perception \& Psychophysics, 1975, 18, 1-8.

GibBon, J. Two kinds of ambiguity in the study of psychological time. In M. L. Commons \& J. A. Nevin (Eds.), Quantitative analysis of behavior: Discriminative properties of reinforcement. Cambridge: Harper \& Row, 1981.

GREEN, D. M., \& LUCE, R. D. Variability of magnitude estimates: A timing theory analysis. Perception \& Psychophysics, 1974, 15, 291-300.

Green, D. M., Luce, R. D., \& Duncan, J. E. Variability and sequential effects in magnitude production and estimation of auditory intensity. Perception \& Psychophysics, 1977, 22, 450-456.

Hollander, M., \& Wolfe, D. A. Nonparametric statistical methods. New York: Wiley, 1973.

HopkINs, G. W. Ultrastable response-stimulus synchronization. Unpublished doctoral dissertation, McMaster University, 1982.

Hopkins, G. W., \& Kristorferson, A. B. Ultrastable stimulusresponse latencies: Acquisition and stimulus control. Perception A Psychophysics, 1980, 27, 241-250.

Jeste ADr, W., Luce, R. D., \& GreEn, D. M. Sequential effects in judgments of loudness. Journal of Experimental Psychology: Human Perception and Performance, 1977, 3, 92-104.

JoHN, I. D. The properties of distributions of magnitude estimates of loudness and softness. Scandinavian Journal of Psychology, 1971, 12, 261-270.

Johnson, N. L., \& Kotz, S. Continuous univariate distributions. New York: Houghton Mifflin, 1970.

Jones, A., \& MacLean, M. Perceived duration as a function of auditory stimulus frequency. Journal of Experimental Psychology, 1966, 71, 358-364.

Kendall, M., \& Stuart, A. The advanced theory of statistics (4th ed.). New York: Macmillan, 1977.

Kinchla, J. Duration discrimination of acoustically defined intervals in the 1- to 8-sec range. Perception \& Psychophysics, $1972,12,318-320$.
KRIBTOFferson, A. B. Low-variance stimulus-response latencies: Deterministic internal delays? Perception \& Psychophysics, 1976, 20, 89-100.

Kristofferson, A. B. A real-time criterion theory of duration discrimination. Perception \& Psychophysics, 1977, 21, 105-117.

Kristofferson, A. B. A quantal step function in duration discrimination. Perception \& Psychophysics, 1980, 27, 300-306.

Künnapas, T., Hallsten, L., \& Söderaera, G. Interindividual differences in homomodal and heteromodal scaling. Acta Psychologica, 1973, 37, 31-42.

Luce, R. D., \& Mo, S. S. Magnitude estimation of heaviness and loudness by individual subjects: A test of a probabilistic response theory. British Journal of Mathematical and Statistical Psychology, 1965, 18, 159-174.

Marks, L. E. Sensory processes. New York: Academic Press, 1974.

Marks, L. E., \& Stevens, J. C. The form of the psychophysical function near threshold. Perception \& Psychophysics, 1968, 4, 315-318.

Mashhour, M., \& Hosman, J. On the new "psychophysical law": A validation study. Perception \& Psychophysics, 1968, 3, 367-375.

Michon, J. A. Magnitude scaling of short durations with closely spaced stimuli. Psychonomic Science, 1967, 9, 359-360.

Montoomery, H. Direct estimation: Effect of methodological factors on scale type. Scandinavian Journal of Psychology, 1975, 16, 19-29.

Montoomeny, H., \& Eisien, H. Is an equal interval scale an equal discriminability scale? Perception \& Psychophysics, 1974, 15, $441-448$.

Painton, S. W., Cullinan, W. L., \& Mencre, E. O. Individual pitch functions and pitch-duration cross-dimensional matching. Perception \& Psychophysics, 1977, 21, 469-476.

Pearson, E. S., D'Agostino, R. B., \& Bowman, K. O. Tests for departure from normality: Comparison of powers. Biometrika, 1977, 64, 231-246.

Plate, J. R. Temporal differentiation and the psychophysics of time. In M. D. Zeiler \& P. Harzem (Eds.), Advances in analysis of behavior: Reinforcement and organization of behavior. London: Wiley, 1979.

Pradhan, P. L., \& Hofrman, P. J. Effect of spacing and range of stimuli on magnitude estimation judgments. Journal of Experimental Psychology, 1963, 66, 533-541.

Rule, S. J., LAYE, R. C., \& Curtis, D. W. Magnitude judgments and difference judgments of lightness and darkness: $A$ two stage analysis. Journal of Experimental Psychology, 1974, 103, 1108-1114.

Shanteau, J. Correlation as a deceiving measure of fit. Bulletin of the Psychonomic Society, 1977, 10, 134-136.

Steiner, S. Apparent duration of auditory stimuli. Journal of Auditory Research, 1968, 8, 195-205.

STEvens, J. C. A comparison of ratio scales for the loudness of white noise and the brightness of white light. Unpublished doctoral dissertation, Harvard University, 1957.

Stevens, J. C. Stimulus spacing and the judgment of loudness. Journal of Experimental Psychology, 1958, 56, 246-250.

Stevens, B. S. On the averaging of data. Science, 1955, 121, 113-116.

Stevens, S. S. On the psychophysical law. Psychological Review, 1957, 64, 153-181.

STEvens, S. S. The psychophysics of sensory function. In W. A. Rosenblith (Ed.), Sensory communication. Cambridge, Mass: MIT Press, 1961.

Strevens, S. S. Issues in psychophysical measurement. Psychological Review, 1971, 78, 426-450.

Stevens, S. S. Psychophysics. New York: Wiley, 1975.

Stevens, S. S., Carton, A. S., \& Shickman, G. M. A scale of apparent intensity of electric shock. Journal of Experimental Psychology, 1958, 56, 328-334.

Stevens, S. S., \& Galanter, E. H. Ratio scales and category scales for a dozen perceptual continua. Journal of Experimental Psychology, 1957, 54, 377-411. 
Stevens, S. S., \& Greenbaum, H. B. Regression effect in psychophysical judgment. Perception \& Psychophysics, 1966, 1, 439-446.

Stevens, S. S., \& Guirao, M. Loudness, reciprocality, and partition scales. Journal of the Acoustical Society of America, $1962,34,1466-1471$.

WARD, L. M. Some psychophysical properties of category judgments and magnitude estimations. Unpublished doctoral dissertation, Duke University, 1971.

WARD, L. M. Repeated magnitude estimates with a variable standard: Sequential effects and other properties. Perception \& Psychophysics, 1973, 13, 193-200.

WARD, L. M. Stimulus information and sequential dependencies in magnitude estimation and cross-modality matching. Journal of Experimental Psychology: Human Perception and Performance, $1979,5,444-459$.

\section{NOTES}

1. Occasionally, subjects failed to respond to one stimulus in a block. In five cases it was clear which stimulus was missed, and the missing response was set equal to the median response emitted by that subject in that block to that stimulus. In one case it was not clear which stimulus was missed, and that block was excluded. One subject failed to respond to many stimuli. His data are not reported.

2. For completeness, we did carry out many of the analyses on both arithmetic and geometric means. While the absolute values of some of the parameter estimates did change, the nature of the trends remained the same.

3. We are aware of the criticisms by Birnbaum (1973), Shanteau (1977), and others of $r^{2}$ as a measure of goodness-of-fit. The alternative of the functional measurement approach (see Anderson,
1977) that they propose is inappropriate for our purpose. We explored the procedure used by Mashhour and Hosman (1968) and Pradham and Hoffman (1963) which involves evaluating goodnessof-fit by constructing confidence intervals around the regression line. Our standard errors are so small that, by this measure, all the equations provide poor descriptions of the data. For example, in Figure $1 b$ the solid line represents the linear function for P.V.O.'s FR data. The mean response to the 20 -msec duration deviates from the line by more than $\mathbf{4 2}$ standard error units! The value of $r^{2}$ is 1.000 .

4. The program used was a translation of F. S. Wood's Nonlinear Least Squares Program (Daniel \& Wood, 1971; SHARE 360D-13.6.007; VIM G2-CAL-NLWOOD) from FORTRAN IV into OS/8 FORTRAN II, with a modification to allow for weighting. It is based on Marquardt's algorithm, which is generally rated as slower, but more likely to converge on a solution, than many others (see Bard, 1974; Beck \& Arnold, 1977; Chambers, 1977 , for reviews).

5. Given nonhomogeneity of variance over stimulus duration, we also fit the two-parameter power function (Equation 3) and the three-parameter power function (Equation 7) using weighted (by variance) nonlinear least squares. Three response distributions had zero variance, and the response weight was fixed at four times the magnitude of the next largest weight. This solution is arbitrary, but it does ensure heavy weighting to the invariant data. In general, the weighted exponents were smaller than the unweighted exponents. The median (mean) weighted two-parameter exponent was $.80(.76)$ and $.87(.83)$ for unweighted, and the median (mean) weighted three-parameter exponent was $.88(.89)$ and $.93(.95)$ for unweighted.

(Manuscript received June 7, 1982;

revision accepted for publication October 25,1982 .) 